\title{
Karyotypic variation in Rhinophylla pumilio Peters, I 865 and comparative analysis with representatives of two subfamilies of Phyllostomidae (Chiroptera)
}

\author{
Anderson José Baia Gomes', Cleusa Yoshiko Nagamachi', \\ Luís Reginaldo Ribeiro Rodrigues², Solange Gomes Farias ${ }^{3}$, \\ Jorge Dores Rissino', Julio Cesar Pieczarka'
}

I Laboratory of Cytogenetics, ICB. Guamá Campus, UFPA. Perimetral Avenue, sn. Belém, PA, Brazil, 660759002 Laboratory of Genetics and Biodiversity, UFOPA, Tapajós Campus. Vera Paz Street, sn, Salé district, Santarém, PA, Brazil. 68.035-150 3 Mammals Collection, Santa Cruz State University, UESC. Ilheus-Itabuna Highway, sn. Itabuna district. Ilhéus, BA, Brazil. 45650-000

Corresponding author: Julio Cesar Pieczarka (julio@ufpa.br)

Academic editor: A. Polyakov | Received 8 July 2011 | Accepted 24 February 2012 | Published 23 May 2012

Citation: Gomes ASB, Nagamachi CY, Rodrigues LRR, Farias SG, Rissino JD, Pieczarka JC (2012) Karyotypic variation in Rhinophylla pumilio Peters, 1865 and comparative analysis with representatives of two subfamilies of Phyllostomidae (Chiroptera). Comparative Cytogenetics 6(2): 213-225. doi: 10.3897/CompCytogen.v6i2.1679

\begin{abstract}
The family Phyllostomidae belongs to the most abundant and diverse group of bats in the Neotropics with more morphological traits variation at the family level than any other group within mammals. In this work, we present data of chromosome banding (G, C and Ag-NOR) and Fluorescence In Situ Hybridization (FISH) for representatives of Rhinophylla pumilio Peters, 1865 collected in four states of Brazil (Amazonas, Bahia, Mato Grosso and Pará). Two karyomorphs were found in this species: 2n=34, FN=64 in populations from western Pará and Mato Grosso states and 2n=34, FN=62 from Amazonas, Bahia, and northeastern Pará and Marajó Island (northern). Difference in the Fundamental Number is determined by variation in the size of the Nucleolar Organizer Region (NOR) accompanied with heterochromatin on chromosomes of pair 16 or, alternatively, a pericentric inversion. The C-banding technique detected constitutive heterochromatin in the centromeric regions of all chromosomes and on the distal part of the long arm of pair 15 of specimens from all localities. FISH with a DNA telomeric probe did not show any interstitial sequence, and an $18 \mathrm{~S}$ rDNA probe and silver staining revealed the presence of NOR in the long arm of the pair 15, associated with heterochromatin, and in the short arm of the pair 16 for all specimens. The intra-specific analysis using chromosome banding did not show any significant difference between the samples. The comparative analyses using G-banding have shown that nearly all chromosomes
\end{abstract}

Copyright Anderson José Baia Gomes et al. This is an open access article distributed under the terms of the Creative Commons Attribution License 3.0 (CC-BY), which permits unrestricted use, distribution, and reproduction in any medium, provided the original author and source are credited. 
of R. pumilio were conserved in the chromosome complements of Glossophaga soricina Pallas, 1766, Phyllostomus hastatus Pallas, 1767, Phyllostomus discolor Wagner, 1843 and Mimon crenulatum Geoffroy, 1801, with a single chromosomal pair unique to $R$. pumilio (pair 15). However, two chromosomes of M. crenulatum are polymorphic for two independent pericentric inversions. The karyotype with $2 \mathrm{n}=34, \mathrm{NF}=62$ is probably the ancestral one for the other karyotypes described for $R$. pumilio.

\section{Keywords}

Biodiversity, Amazon rainforest, Chiroptera, cytogenetics

\section{Introduction}

Traditionally, the subfamily Carolliinae (sensu Wetterer et al. 2000) encompasses two genera: Carollia Gray, 1838 (10 species) and Rhinophylla Peters, 1865 (3 species) with wide distribution throughout South America. Rhinophylla consists of the smallest animals in the subfamily and has three currently recognized species: Rhinophylla pumilio Peters, 1865 and Rhinophylla fischerae Carter, 1966, with distribution on the east side of Andes in South America, and Rhinophylla alethina Handley, 1966 with distribution on the Pacific slope and lowlands of Colombia and Ecuador (McLellan and Koopman 2007).

Cytogenetic studies in Carolliinae have shown different rates of chromosomal evolution between both genera. The genus Carollia has two karyomorphs: $2 \mathrm{n}=20 / 21$ with a multiple sex chromosome system $\left(\mathrm{XX} / \mathrm{XY}_{1} \mathrm{Y}_{2}\right)$, observed in most species (Yonenaga et al. 1969, Pathak et al. 1973, Stock 1975, Baker 1979, Varella-Garcia et al. 1989, Pieczarka et al. 2005), and $2 \mathrm{n}=22$ with simple sex chromosome system found only in Carollia benkeithi Solari \& Baker, 2006. On the other hand, the genus Rhinophylla has diversified karyotypes with four karyomorphs for $R$. pumilio (Tables 1 and 2) and two for $R$. fischerae (Baker and Bleier 1971, Baker 1979, Baker et al. 1987, Gomes et al. 2010). No karyotype has been described for $R$. alethina.

The monophyly of the subfamily Carolliinae and the sister-group relationships of Carollia and Rhinophylla have been supported by a phylogenetic analysis based on morphological data (Baker et al. 1989, Wetterer et al. 2000, Jones et al. 2002), however molecular data are in disagreement with the advanced hypotheses (Wright et al. 1999, Baker et al. 2000, 2003b). Additionally, classical cytogenetic markers failed to provide a support for the phylogenetic relationships between Carollia and Rhinophylla, since the chromosomal homeologies could not be assigned because of the reshuffled genome of Carollia. In contrast, Rhinophylla is quite comparable to other lineages and shares a lot of chromosomal characters with representatives of the subfamilies Phyllostominae, Glossophaginae, Stenodermatinae and Desmodontinae (Baker and Bickham 1980, Baker et al. 1987, 1989).

Therefore, we analyzed, through conventional cytogenetic (G-, C- banding and Ag-NOR staining) techniques and Fluorescence In Situ Hybridization (FISH) with rDNA and Telomere probes, two karyotypes of $R$. pumilio and discussed the biogeographical chromosome variation by comparing karyotypes of this species with representatives of two subfamilies of Phyllostomidae (Glossophaginae and Phyllostominae). 


\section{Material and methods}

\section{Specimens analyzed}

Cytogenetic preparations of $R$. pumilio were obtained from 40 specimens collected in four states in Brazil: Pará state -16 males and 13 females, Amazonas state -1 male and 4 females, Mato Grosso state -1 male and 4 females, Bahia state -1 male (Fig. 1, Table 1). The bats were collected in the field using mist nets during the expeditions to faunal inventories. Comparative cytogenetic analyses were performed with Glossophaga soricina Pallas, 1766 (from Santa Barbara), Phyllostomus hastatus Pallas, 1767 (from Peixe-Boi), Phyllostomus discolor Wagner, 1843 (from Belém) and Mimon crenulatum Geoffroy, 1801 (from Faro). Chromosomal preparations and tissue biopsies were sent to the Cytogenetics Laboratory at Universidade Federal do Pará. Animals were fixed in $10 \%$ formalin preserved in $70 \%$ ethanol and deposited in the mammal's collection of the Museum Paraense Emilio Goeldi, mammal's collection of the Santa Cruz State University, Ilhéus-Bahia, Zoology Museum of the Mato Grosso Federal University and Zoology Museum of the West Pará Federal University.

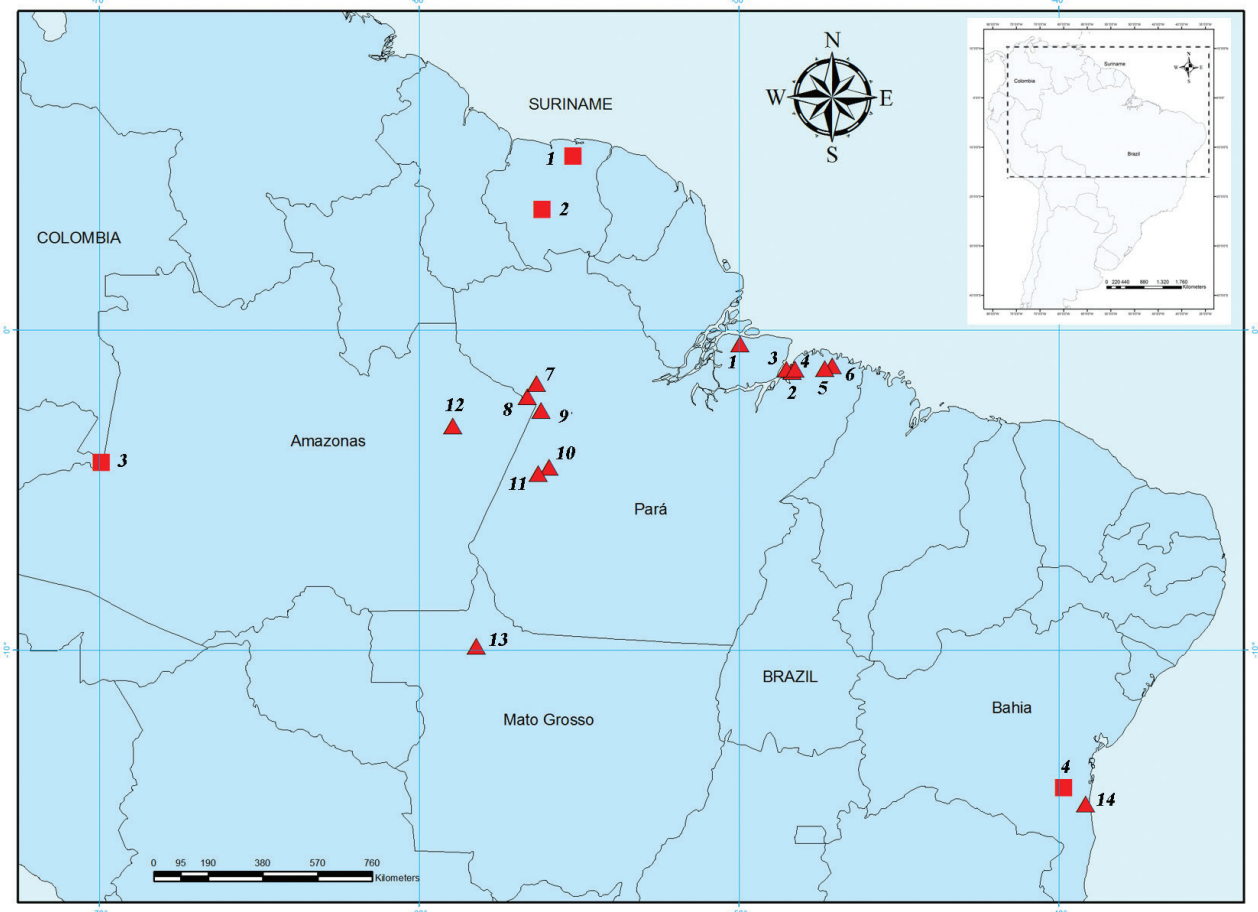

Figure I. Map of collected samples of Rhinophylla pumilio. Squares indicate the sites from where previous cytogenetic descriptions were performed whereas triangles represent the cytogenetic samples studied herein (see Tables 1 and 2 for locality details). Numbers of sites correspond to numbers on Tables 1 and 2 . 
Table I. Cytogenetic samples of Rhinophylla pumilio from different localities. Numbers of sites correspond to numbers of triangles on the map (Fig. 1).

\begin{tabular}{|c|c|c|c|c|c|}
\hline Site & $\mathbf{n}$ & Locality/State & 2N/FN & Methods & Geographical coordinates \\
\hline 1 & $1 \hat{0}+1+q$ & Chaves, Pará & $34 / 62$ & $\mathrm{G}$ & $00^{\circ} 24^{\prime} 55.3^{\prime \prime S}$; $49^{\circ} 58^{\prime} 44.1^{\prime \prime W}$ \\
\hline 1 & 39 & & $34 / 62$ & & \\
\hline 2 & $10^{1}$ & Marituba, Pará & $34 / 62$ & G, C & $01^{\circ} 16^{\prime} 37.5^{\prime \prime S} ; 48^{\circ} 20^{\prime} 14.9^{\prime \prime W}$ \\
\hline 3 & $10^{\lambda}$ & Belém, Pará & $34 / 62$ & $\begin{array}{l}\text { G, C, NOR, Telomere, } \\
\text { rDNA, CMA3 }\end{array}$ & $01^{\circ} 13^{\prime} 29.3^{\prime \prime} \mathrm{S} ; 48^{\circ} 32^{\prime} 59.0^{\prime \prime} \mathrm{W}$ \\
\hline 3 & $10^{1}$ & & $34 / 62$ & G, C & \\
\hline 4 & $1 \hat{0}+1$ + & Santa Barbara, Pará & $34 / 62$ & G & $01^{\circ} 13^{\prime} 57.4^{\prime \prime S} ; 48^{\circ} 16^{\prime} 34.4^{\prime \prime W}$ \\
\hline 4 & $4 \hat{0}+2+$ & & $34 / 62$ & & \\
\hline 5 & 19 & Capanema, Pará & $34 / 62$ & C & $01^{\circ} 24^{\prime} 02.5^{\prime \prime S} ; 48^{\circ} 29^{\prime} 02.4^{\prime \prime W}$ \\
\hline 6 & $10^{\pi}$ & Peixe-Boi, Pará & $34 / 62$ & G, C & $01^{\circ} 11^{\prime} 11.0^{\prime \prime S} ; 47^{\circ} 19^{\prime} 28.5^{\prime \prime W}$ \\
\hline 6 & $10^{1}$ & & $34 / 62$ & G, C, rDNA, CMA3 & \\
\hline 7 & $2 \hat{O}+1 q$ & Oriximiná, Pará & $34 / 62$ & G, C & $01^{\circ} 39^{\prime} 03.3^{\prime \prime S} ; 56^{\circ} 20^{\prime} 30.6^{\prime \prime W}$ \\
\hline 8 & 19 & Faro, Pará & $34 / 62$ & G, C & $02^{\circ} 03^{\prime} 53.1^{\prime \prime S} ; 56^{\circ} 37^{\prime} 57.4^{\prime \prime W}$ \\
\hline 9 & $10^{1}$ & Juruti, Pará & $34 / 64$ & G, C, NOR, rDNA & $02^{\circ} 29^{\prime} 38.8^{\prime \prime S} ; 56^{\circ} 11^{\prime} 27.1^{\prime \prime W}$ \\
\hline 9 & 19 & & $34 / 64$ & $\mathrm{G}, \mathrm{C}, \mathrm{rDNA}$ & \\
\hline 10 & 19 & Itaituba, Pará & $34 / 64$ & & $04^{\circ} 16^{\prime} 26.6^{\prime \prime S} ; 55^{\circ} 56^{\prime} 47.6^{\prime \prime W}$ \\
\hline 10 & $10^{1}$ & & $34 / 64$ & G, C, rDNA, CMA3 & \\
\hline 11 & $1 \hat{0}+1$ + & Itaituba, Pará & $34 / 64$ & $\mathrm{G}, \mathrm{C}$ & $04^{\circ} 28^{\prime} 20.5^{\prime \prime S} ; 56^{\circ} 17^{\prime} 03.7^{\prime \prime W}$ \\
\hline 12 & $1 \hat{0}^{\lambda}+3+$ & Itacoatiara, Amazonas & $34 / 62$ & G, C & $02^{\circ} 58^{\prime} 49.6^{\prime \prime S} ; 58^{\circ} 57^{\prime} 51.0^{\prime \prime W}$ \\
\hline 12 & $1+$ & & $34 / 62$ & & \\
\hline 13 & $1 \hat{\sigma}^{\lambda}+4$ 우 & $\begin{array}{l}\text { Potriguaçú, Mato } \\
\text { Grosso }\end{array}$ & $34 / 64$ & G, C & $09^{\circ} 51^{\prime} 53.7^{\prime \prime S} ; 58^{\circ} 13^{\prime} 06.8^{\prime \prime W}$ \\
\hline 14 & 10 & Ilhéus, Bahia & $34 / 62$ & G, C, NOR & $14^{\circ} 47^{\prime} 52.0^{\prime \prime S} ; 39^{\circ} 10^{\prime} 15.0^{\prime \prime} \mathrm{W}$ \\
\hline
\end{tabular}

\section{Chromosomal preparation and cell culture}

The chromosome spreads were obtained from bone marrow following Baker et al. (2003a) and fibroblast primary culture following the protocols by Moratelli et al. (2002), and conventionally stained. The G-banding patterns were obtained with pepsin solution, subsequent incubation in saline solution $(0,5 \mathrm{X} \mathrm{SSC})$ at $60^{\circ} \mathrm{C}$ and staining with Wright's solution following Verma and Babu (1995). The C-banding was carried out following Sumner (1972), detection of Nucleolar Organizer Regions was performed according to Howell and Black (1980) and double staining with DAPI $\mathrm{CMA}_{3}$ was performed according to Schweizer (1980).

\section{Fluorescence In Situ Hybridization (FISH)}

Fluorescence In Situ Hybridization using digoxigenin-labeled telomeric probes (All Human Telomere Probes, Oncor) was performed according to the manufacturer's protocol. To confirm the position of the NORs, $18 \mathrm{~S}$ rDNA probes were amplified by 
BACs (Bacterial Artificial Chromosomes), labeled by nick translation and subsequently detected with avidin-Cy3 or anti-digoxigenin- FITC. Briefly, the slides were incubated in RNAse and pepsin solutions following Martins and Galetti (1998). The slides were dehydrated in ethanol series $(70 \%, 90 \%$ and $100 \%)$, aged in a $65^{\circ} \mathrm{C}$ incubator for one hour, and denatured in $70 \%$ formamide/ 2 X SSC for one minute. The labeled probe $(2 \mu \mathrm{l})$ was diluted in $10 \mu \mathrm{l}$ of hybridization buffer $(50 \%$ deionized formamide, $10 \%$ dextran sulfate, $0,5 \mathrm{M}$ phosphate buffer 7,3 $\mathrm{pH}, 1 \mathrm{x}$ Denhardt's solution), denatured at $70^{\circ} \mathrm{C}$ for 15 minutes, and dropped on the slide with the denatured chromosome preparation, which was then mounted with a $24 \times 24 \mathrm{~mm}$ coverslip. Slides then were incubated overnight at $37^{\circ} \mathrm{C}$. The hybridization signal was detected with avidin-Cy3 as described previously (Yang et al. 1995, Pieczarka et al. 2005). The images were captured with an Axiocam Mrm CCD camera coupled on a Zeiss Axioplan 2 microscope using the Axiovision 3.0 software. The chromosomes were identified according to their morphology and inverted banding patterns using DAPI (4',6-diamidino-2-phenylindole).

\section{Results}

All studied specimens of $R$. pumilio have the same chromosome number $-2 \mathrm{n}=34$. The autosomal complement consists of 15 pairs biarmed (metacentric and submetacentric) and one pair of acrocentric chromosomes (pair 16) in samples collected from Bahia, Amazonas, northeastern Pará and Marajó Island (north of Para) (Fig. 2a). In contrast, the chromosome pair 16 of specimens from west Pará and Mato Grosso is biarmed (Fig. 3a). The $\mathrm{X}$ chromosome is a medium-sized metacentric chromosome and the $Y$ is a small acrocentric.

The constitutive heterochromatin was found in the centromeric regions of all chromosomes and at the distal part of the long arm of pair 15 for all specimens (Fig. 2b). Telomere sequences were observed at the tips of chromosomes (Fig. 2d). The rDNA probes and staining with silver nitrate confirmed the presence of NORs in the long arm of the pair 15 and short arm of the pair 16 (Fig. 2c). The FISH with rDNA and subsequent double staining with DAPI and $\mathrm{CMA}_{3}$ are in agreement with the patterns of G-bands and R-bands, respectively, where the R-bands show the tips of the chromosomes and its association with the NOR (Fig. 3b).

The comparative analysis with $P$. hastatus, $P$. discolor, M. crenulatum (Phyllostominae) and G. soricina (Glossophaginae) (Fig. 4a) suggests that the karyotypes of $R$. pumilio here described have nearly all chromosome pairs shared with these species, although one pair was autapomorphic to $R$. pumilio (Fig. 4b). Analyzed species are different in the number of chromosomes (34 in $R$. pumilio and 32 in other species) and the fundamental number (58 in P. hastatus, 60 in M. crenulatum, P. discolor, G. soricina and 62/64 in $R$. pumilio). The heterochromatin presents in the centromeric regions of all species with additional blocks in the short and long arms of the 15th pair of $M$. crenulatum and G. soricina, respectively. Chromosomes of 5th and 6th pairs of $M$. crenulatum exhibit two polymorphic conditions derived probably from pericentric 


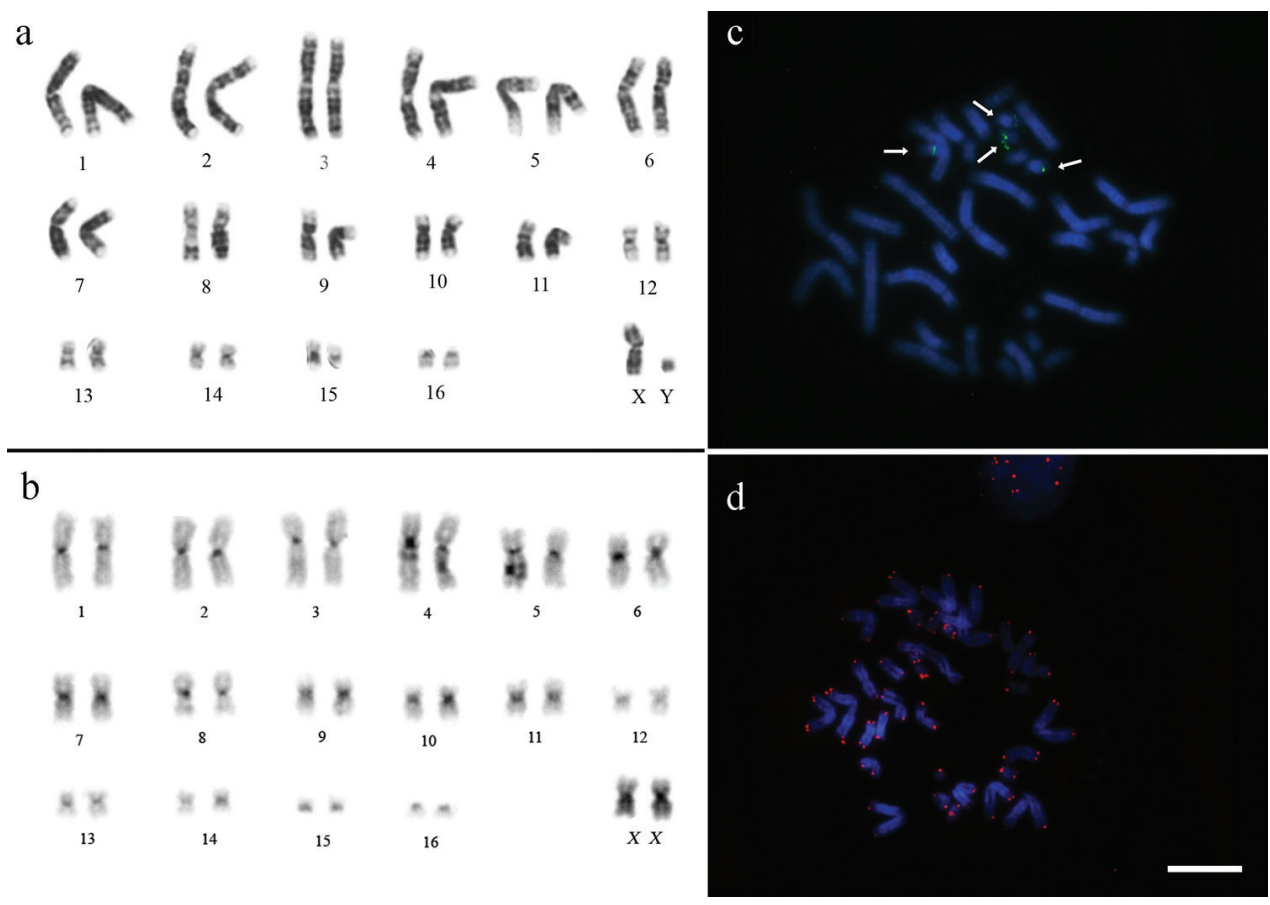

Figure 2. Karyotypes of Rhinophylla pumilio from northeastern Pará (except C-banding obtained from specimens from Amazonas state) a G-banding b C-banding $\mathbf{c} 18 \mathrm{~S}$ rDNA FISH and $\mathbf{d}$ telomeric FISH. Arrows show NORs in the chromosome pairs 15 and 16 . Bar $=10 \mu \mathrm{m}$.

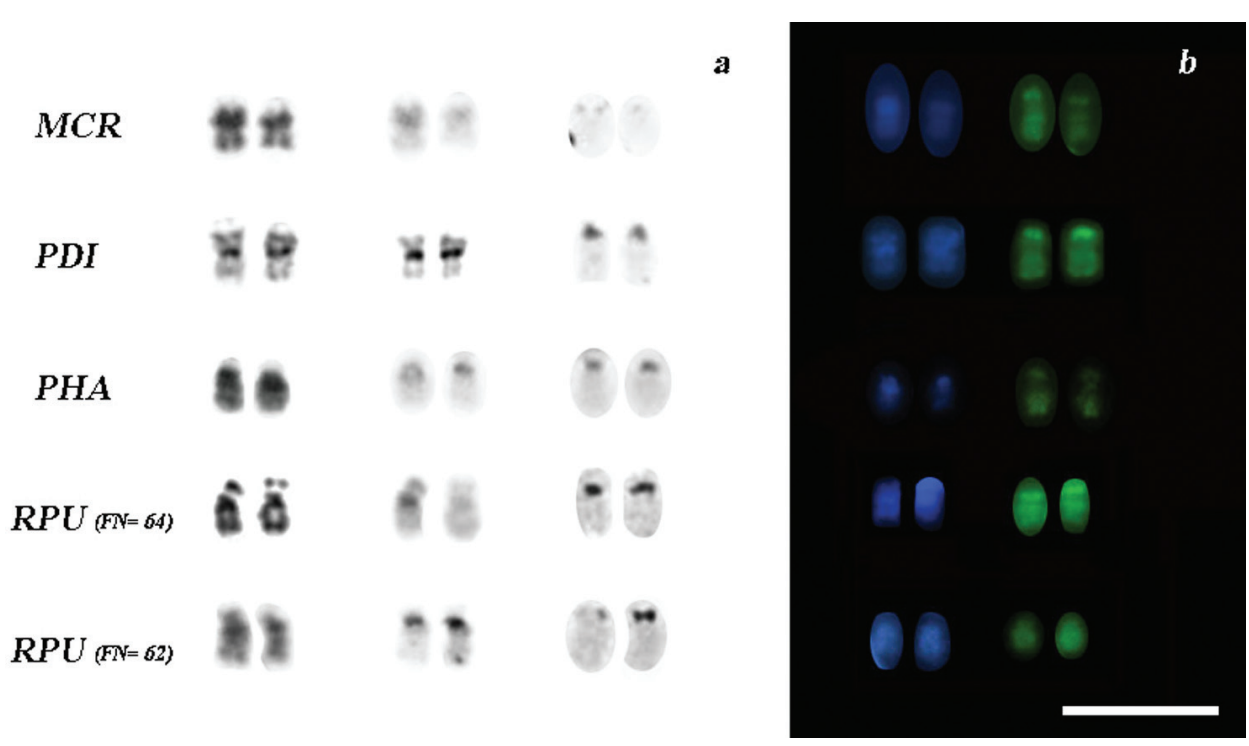

Figure 3. Variation of chromosome pair 15 (16 in Rhinophylla pumilio) in the analyzed species a chromosomes after $\mathrm{G}, \mathrm{C}$ and $\mathrm{Ag}-\mathrm{NOR}$ sequential staining $\mathbf{b}$ patterns of double staining with DAPI-CMA . Bar $=10 \mu \mathrm{m}$. 


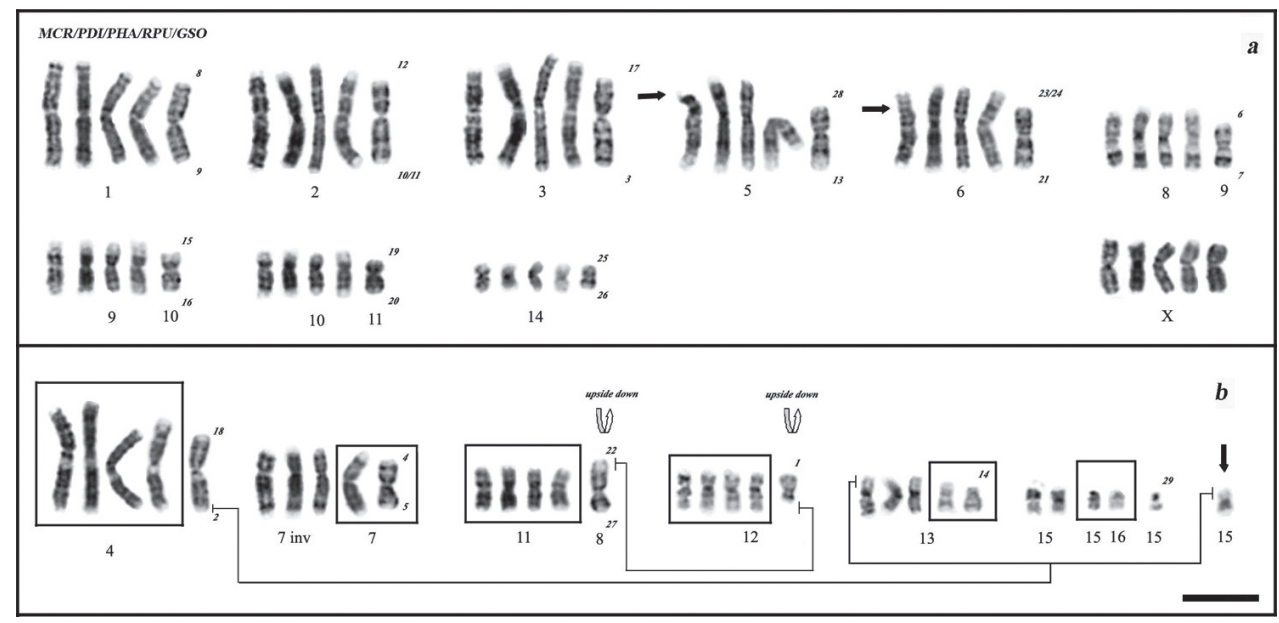

Figure 4. Comparative analysis using G-banded chromosomes of Mimon crenulatum, Phyllostomus discolor, Phyllostomus hastatus, Rhinophylla pumilio and Glossophaga soricina, from left to right a Conserved chromosomes among species, arrows show the centromeric position in $M$. crenulatum $\mathbf{b}$ Chromosomal differences among species. Black arrow indicates autapomorphic chromosome in $R$. pumilio. Numbers (beside G. soricina) correspond to the chromosomal nomenclature applied to arms of Macrotus waterhousii in $G$. soricina according to Baker and Bass (1979). Bar $=10 \mu \mathrm{m}$.

inversions that could cause the acrocentric and subtelocentric forms, respectively. Both specimens are heterozygous for 6th pair and homozygous for normal and rearranged forms of 5th chromosome pair. The NORs in this species are localized in the short arm of 15 th pair and in the $Y$ chromosome.

\section{Discussion}

\section{Intraspecific variation in Rhinophylla pumilio}

Our G-, C-, and Ag-NOR banding analyses have shown two distinct karyotypes for specimens of $R$. pumilio from localities ranging more than $1000 \mathrm{~km}$. The differences between these karyotypes may be caused by a pericentric inversion in the chromosome pair 16 or, alternatively, an amplification of rDNA cistrons accompanied with a faint block of heterochromatin in $R$. pumilio with $\mathrm{FN}=64$ (Fig. 3a). This segment is coincident with $\mathrm{CMA}_{3}$ positive staining for NOR and DAPI positive to the heterochromatic block (Fig. 3b).

Comparative analysis of karyotypes from different geographic localities (Table 2) allows discussing the morphology and number of chromosomes. Since only data of conventional staining or karyotype formula were described in the literature we had to restrict our comparisons to number and basic morphology of chromosomes. In this way, specimens of $R$. pumilio collected on the Marajó island and northeastern Pará (Fig. 1, triangles 1, 2, 3, 4, 5, and 6) in the left side of the Amazon basin on Pará and 
Table 2. Previous cytogenetic studies on Rhinophylla pumilio. Numbers of sites correspond to numbers of squares on the map (Fig. 1).

\begin{tabular}{|c|c|c|c|c|}
\hline Site & Region & Geographical coordinates & 2n/FN & References \\
\hline 1 & Suriname & $05^{\circ} 27^{\prime} 00^{\prime \prime}$; $55^{\circ} 12^{\prime} 00^{\prime \prime W}$ & $34 / 64$ & Honeycutt et al. 1980, Baker et al. 1981 \\
\hline 2 & Suriname & $03^{\circ} 46^{\prime} 00^{\prime \prime} \mathrm{S} ; 56^{\circ} 10^{\prime} 00^{\prime \prime} \mathrm{W}$ & $34 / 56$ & Baker and Bickham 1980 \\
\hline 3 & Colombia & $04^{\circ} 07^{\prime} 43^{\prime \prime} \mathrm{S} ; 69^{\circ} 56^{\prime} 37^{\prime \prime W}$ & $36 / 62$ & Baker and Bleier 1971 \\
\hline 4 & Brazil-Bahia & $14^{\circ} 17^{\prime} 29^{\prime \prime S} ; 39^{\circ} 51^{\prime} 18^{\prime \prime W}$ & $26 / 48$ & Toledo 1973 \\
\hline
\end{tabular}

Amazonas (triangles 7, 8 and 12) and Bahia (triangle 14) have 2n=34 and FN=62. Meanwhile, the samples from western Pará (triangles 9, 10 and 11) and Mato Grosso (triangle 13) presented the same fundamental number as specimens collected from Suriname, with $2 \mathrm{n}=34, \mathrm{FN}=64$ (Honeycutt et al. 1980, Baker et al. 1981, square 1).

Karyotype with $2 \mathrm{n}=26$ and $\mathrm{FN}=48$ described by Toledo (1973) (Fig. 1, Bahia, square 4) was found only in $100 \mathrm{~km}$ from the collection site of our sample with $2 \mathrm{n}=34$ and NF=62. Varella-Garcia et al. (1989) suggested that the chromosome differences between populations of $R$. pumilio described by Toledo (1973) and Baker and Bleier (1971) would be enough to reach the reproductive isolation between them. Nevertheless, analysis of mithocondrial DNA did not reveal sufficient genetic distance $(0,3 \%)$ between two specimens from Northeastern Brazil (Pernambuco and Bahia) (Ditchfield 2000). Such distance is commonly observed within a breeding population. A re-analysis of the chromosome data from Toledo (1973) showed a disagreement with respect to the small size of the $\mathrm{X}$ chromosome and discordant number of chromosomes in mitotic and meiotic cells.

Another cytogenetic study on specimens of $R$. pumilio from Colombia described a karyotype with 2n=36 and FN=62, (Baker and Bleier 1971, Fig. 1, square 3), differing from populations with $2 \mathrm{n}=34$ and $\mathrm{FN}=62$ probably by a chromosome fusion/fission event. Bats with karyotypes $2 \mathrm{n}=34, \mathrm{FN}=56$ (Baker and Bickham 1980, square 2) and 2n=34, FN=64 (Honeycutt et al. 1980, Baker et al. 1981, square 1) could be probably found in sympatry on the territory of Suriname.

\section{Intergeneric comparative analysis}

Comparative analysis of chromosome banding patterns of $R$. pumilio was undertaken with representatives of two other subfamilies of Phyllostomidae bats: P. hastatus, P. discolor, M. crenulatum (Phyllostominae) and G. soricina (Glossophaginae). Karyotypes of these species supposed to be ancestral for their respective subfamilies (Patton and Baker 1978, Baker and Bass 1979, Baker and Bickham 1980, Haiduk and Baker 1982, Baker et al. 1989) and karyotype of $R$. pumilio with $2 \mathrm{n}=34$ and $\mathrm{FN}=56$ described by Baker and Bickham (1980) revealed several characters shared with the above mentioned species.

Comparative analysis revealed that there are an extensive number of conserved chromosomes shared among these species. However, R. pumilio shared more charac- 
ters with Phyllostominae species than G. soricina (Fig. 4b). Based on outgroup comparisons, Baker and Bickham (1980) proposed that the most primitive karyotype for the family Phyllostomidae is identical to that of Macrotus waterhousii Gray, 1843. This hypothesis together with the basal position of $M$. waterhousii in recent phylogenies (Baker et al. 2000, 2003b, Datzmann et al. 2010) allows to suppose the most basal nature of chromosome pairs 12 and $8 \mathrm{q}$ of G. soricina because they are homologous to the acrocentric element 22 and to short arm of the biarmed element $1 / 2$ of $M$. waterhousii, respectively (in Baker and Bass 1979). However, we suggest that in the basal branch that led to peculiarity of chromosome pairs 11 and 12 of $P$. hastatus, $P$. discolor, $M$. crenulatum and $R$. pumilio, the same chromosomes ( 12 and $8 \mathrm{q}$ of $G$. soricina) could be involved in a simple translocation from a segment on the long arm of pair 8 to short arm of the pair 12 of $G$. soricina. Alternatively, the same chromosomes would be synapomorphic in G. soricina, as well as in some species of the Glossophaginae subfamily, and symplesiomorphic in other species analyzed here.

Furthermore, other differences among karyotypes (Fig. 4b) are a pericentric inversion on pair 7 of P. hastatus (Patton and Baker 1978) and a simple translocation involving the pairs 4 and 13 of this species as was observed by Pieczarka et al. (2005). Such events are symplesiomorphic in G. soricina, synapomorphic in Phyllostominae species and probably autoapomorphic in $R$. pumilio (pair 15). Integration of data derived from multidirectional chromosome painting with chromosome probes of Carollia brevicauda Schinz, 1821 and $P$. hastatus on metaphase spreads of G. soricina and chromosome map using probes of human chromosomes in the last species (Volleth et al. 1999) have shown that the basal position of G. soricina is supported by the fact that the pair 6 of human chromosomes was not disrupted. This chromosome has been assumed to be disrupted and subsequently fused with chromosome 13 of the Phyllostominae group, whereas this small segment forms an independent pair 15 in $R$. pumilio (unpublished data).

Another interesting problem in our comparative analysis is the pair 16 in $R$. pumilio, which has two chromosomal traits similar to those observed within representatives of genus Phyllostomus Lacépède, 1799. The difference between the karyotypes of $P$. hastatus and $P$. discolor consists of a pericentric inversion of the pair 15 (Patton and Baker 1978, Rodrigues et al. 2000). This chromosome is biarmed in P. discolor and acrocentric in P. hastatus, P. elongatus Geoffroy, 1810, P. latifolius_Thomas, 1901 and Phylloderma stenops Peters, 1865 (Baker 1979, Baker and Bickham 1980, Honeycutt et al. 1980, Santos et al. 2002). Rodrigues et al. (2000) suggested that the biarmed state of pair 15 of $P$. discolor could be most basal, because it has been shared with $M$. crenulatum, considered the most basal for the genus, and because this chromosome seems to be the result of a fusion of two acrocentric chromosomes of M. waterhousii (Patton and Baker 1978). The other species of Phyllostomus along with $P$. stenops form a clade supported by the acrocentric form of the pair 15 . However, the three species analyzed in this work showed different forms of the biarmed pair 15 (16 in $R$. pumilio). The short arm of $M$. crenulatum represents a block of heterochromatin followed by the NOR, whereas in $R$. pumilio the NOR appears before the heterochromatin. On the other hand, in G. soricina the NOR is represented at 
the long arm near the centromeric region accompanied by a heterochromatic block. Figure 3 shows the pattern of G- C and NOR sequential staining of pair 15 (16 in $R$. pumilio) as well as the pattern of $\mathrm{A} / \mathrm{T}-\mathrm{G} / \mathrm{C}$ evidenced by double staining with fluorescence DAPI and $\mathrm{CMA}_{3}$. The more plausible explanation is that the biarmness appeared in different branches of Phyllostomidae bats by amplification of rDNA cistrons accompanied or not with addition of heterochromatin, and possibly with other types of rearrangements.

Baker et al. (1972) defined three morphological types (submetacentric, acrocentric and subtelocentric) for the 5th chromosome pair of M. crenulatum at localities encompassing a wide geographic distance (Trinidad, Peru and Colombia). In this work, we have collected two specimens geographically apart from sites studied by Baker et al. (1972). We have found similar morphological types but G-banding analysis revealed that the acrocentric chromosome belonged to the 5th pair and the subtelocentric - to the 6th pair. That means that this polymorphism is defined by two pairs of chromosomes instead of one as it was suggested earlier.

Among species of genus Carollia karyotypes are highly rearranged and after the reciprocal chromosome painting Pieczarka et al. (2005) found only two chromosomes conserved in toto between C. brevicauda (pairs 7 and 9) and P. hastatus (pairs 11 and 14). This finding suggests that they represent probably a part of the ancestral karyotype of Phyllostomidae, since they are preserved in such phylogenetically remote species. In the genus Rhinophylla these shared chromosomes are also presented by pairs 11 and 14 and can be also observed in others species studied herein except for the 8th pair of $G$. soricina that is partially homologous to the 11 th pair of $R$. pumilio. Therefore an analysis of the chromosomes homology among other species, especially those closely related to the genus Carollia, will be necessary to corroborate the sister group relationships of the genus Carollia and Rhinophylla.

Finally, we believe that variation of karyotypes along the area of $R$. pumilio is correlated with intraspecific variation where the karyomorphs would be derived from ancestral karyotype with $2 \mathrm{n}=34, \mathrm{FN}=62$, since this karyotype is similar to other close related species at the chromosome level. However, additional analyses will be necessary to elucidate the biogeographical patterns related to the chromosome variation in $R$. pumilio.

\section{Acknowledgments}

We thank to Manoel Rodrigues (Juris Ambientes Consultores), Flávio Eduardo Pimenta and Ana lima (Aotus Consultoria), Pablo Suarez, Dionísio Pimentel, Heriberto Figueria and the staff of CNEC- Juruti for Help us in the field expedition in the area of Alcoa's Juruti Bauxite mine. We thank to Biodinamica-Rio, Aotus Consultoria and Talita Ribas, Eloiza Soarez, Fabio Sarmento, Fabio Augustos and Ramon Araujo for help us in the bats expedition in the Electric power transmission from Oriximina (Pará state) to Silves (Amazonas state) and Thayse Benathar for the chromosome preparation from Mato Grosso state and in the area TERFRON project on Itaituba. We are grateful 
to Cibele Sotero-Caio for a critical analysis of this work. This research was supported by $\mathrm{CNPq}$ (Conselho Nacional de Desenvolvimento Científico e Tecnológico), CAPES (Conselho Aperfeiçoamento de Pessoal de Nível Superior), UFOPa (Universidade Federal do Oeste do Pará) and UFPa (Universidade Federal do Pará).

\section{References}

Baker RJ, Bleier WJ (1971) Karyotypes of bats of the subfamily Carolliinae (Mammalia; Phyllostomatidae) and their evolutionary implications. Experientia 27: 220-222. doi: 10.1007/BF02145907

Baker RJ, Gardner AL, Patton JL (1972) Chromosomal polymorphism in the phyllostomatid bat, Mimon crenulatum (Geoffroy). Experientia 28: 969-970. doi: 10.1007/BF01924978

Baker RJ, Bass RA (1979) Evolutionary relationship of the Brachyphyllinae to Glossophaginae genera Glossophaga and Monophyllus. Journal of Mammalogy 60: 364-372. doi: $10.2307 / 1379808$

Baker RJ (1979) Karyology. In: Baker RJ, Jones JK Jr., Carter DC (Eds), Biology of the bats of the New World, family Phyllostomatidae, p. III. Special Publications of the Museum of Texas Tech University 16: 1107-155.

Baker RJ, Bickham JW (1980) Karyotipic Evolution in bats: Evidence of extensive and conservative chromosomal evolution in closely related taxa. Systematic Zoology 29: 239-253. doi: $10.2307 / 2412660$

Baker RJ, Genoways HH, Seyfarth PA (1981) Results of the Alcoa Foundation-Suriname Expeditions. VI. Additional chromosomal data for bats (Mammalia: Chiroptera) from Suriname. Annals of Carnegie Museum 50: 333-344.

Baker RJ, Qumsiyeh MB, Hood CS (1987) Role of chromosomal banding patterns in understanding mammalian evolution. In: Genoways HH (Ed) Current Mammalogy. Plenum Press, New York, 67-96.

Baker RJ, Hood CS, Honeycutt RL (1989) Phylogenetic relationships and classification of the higher categories of the New World bat family Phyllostomidae. Systematic Zoology 38: 228-238. doi: 10.2307/2992284

Baker RJ, Porter CA, Patton JC, Van Den Bussche RA (2000) Systematics of bats of the family Phyllostomidae based on RAG2 DNA sequences. Occasional Paper of the Museum of Texas Tech University 202: 1-16.

Baker RJ, Hamilton M, Parish DA (2003a) Preparations of Mammalian karyotypes under field conditions. Occasional Paper of the Museum of Texas Tech University 228: 1-7.

Baker RJ, Hoofer SR, Porter CA, Van Den Bussche RA (2003b) Diversification among New World leaf-nosed bats: an evolutionary hypothesis and classification inferred from digenomic congruence of DNA sequence. Occasional Paper of the Museum of Texas Tech University 230: 1-32.

Datzmann T, Helversen OV, Mayer F (2010) Evolution of nectarivory in phyllostomid bats (Phyllostomidae Gray, 1825, Chiroptera: Mammalia). BMC Evolutionary Biology 10: 165. doi: 10.1186/1471-2148-10-165 
Ditchfield AD (2000) The comparative phylogeography of Neotropical mammals: patterns of intraspecific mitochondrial DNA variation among bats contrasted to nonvolant small mammals. Molecular Ecology 9: 1307-1318. doi: 10.1046/j.1365-294x.2000.01013.x

Gomes AJB, Rodrigues LRR, Rissino JD, Nagamachi CY, Pieczarka JC (2010) Biogeographical karyotypic variation of Rhinophylla fischerae (Chiroptera, Phyllostomidae) suggests the occurrence of cryptic species. Comparative Cytogenetics 4: 79-85. doi: 10.3897/compcytogen.v4i1.24

Haiduk MW, Baker RJ (1982) Cladistical analysis of G-banded chromosomes of nectarfeeding bats (Glossophaginae, Phyllostomidae). Systematic Zoology 31: 252-265. doi: $10.2307 / 2413231$

Honeycutt RL, Baker RJ, Genoways HH (1980) Results of the Alcoa Foundation-Suriname expeditions. III. Chromosomal data for bats (Mammalia: Chiroptera) from Suriname. Annals of Carnegie Museum 49: 237-250.

Howell WM, Black DA (1980) Controlled silver-staining of nucleolar organizer regions with protective colloidal developer: a 1-step method. Experientia 36: 1014-1015. doi: 10.1007/ BF01953855

Jones JK, Purvis A, Maclarnon A, Bininda-Emonds ORP, Simmons NB (2002) A phylogenetic supertree of the bats (Mammalia: Chiroptera). Biological Reviews 77: 223-259. doi: $10.1017 /$ S1464793101005899

Martins C, Galetti PM Jr (1998) Karyotype similarity between two sympatric Schizodon fish species (Anostomidae, Characiformes) from Paraguay River basin. Genetics and Molecular Biology 21: 355-360. doi: 10.1590/S1415-47571998000300011

McLellan LJ, Koopman KF (2007) Subfamily Carolliinae Miller, 1924. In: A. L. Gardner (ed) Mammals of South America. Volume 1. University of Chicago Press, Chicago, 208-218.

Moratelli R, Andrade CM, Armada JLA (2002) A technique to obtain fibroblast cells from skin biopsies of living bats (Chiroptera) for cytogenetic studies. Genetics and Molecular Research 2: 128-130.

Pathak S, Hsu TC, Utakoji T (1973) Relationships between patterns of chromosome banding and DNA synthetic sequences: a study on the chromosomes of the Seba's fruit bat Carollia perspicilata. Cytogenetics and Cell Genetics 12: 157-164. doi: 10.1159/000130451

Patton JC, Baker RJ (1978) Chromosomal homology and evolution of phyllostomatoids bats. Systematic Zoology 27: 449-462. doi: 10.2307/2412927

Pieczarka JC, Nagamachi CY, O’Brien PCM, Yang F, Ren W, Barros RMS, Noronha RCR, Rissino J, Oliveira EHC, Ferguson-Smith MA (2005) Reciprocal chromosome painting between two South American bats: Carollia brevicauda and Phyllostomus hastatus (Phyllostomidae, Chiroptera). Chromosome Research 13: 349-347. doi: 10.1007/s10577-005-2886-0

Rodrigues LRR, Barros RMS, Marques-Aguiar S, Assis MFL, Pieczarka JC, Nagamachi CY (2000) Chromosome comparison between two species of Phyllsotomus (Chiroptera-Phyllostomidae) from Eastern Amazonia, with some phylogenetic insights. Genetics and Molecular Biology 3: 593-599.

Santos N, Fagundes V, Yonenaga-Yassuda Y, Souza MJ (2002) Localization of rDNA genes in Phyllostomidae bats reveals silent NORs in Artibeus obscurus. Hereditas 136: 137-143. doi: 10.1034/j.1601-5223.2002.1360208.x 
Schweizer D (1980) Simultaneous fluorescent staining of R bands and specific heterochromatic region. 1 (DA-DAPI bands) in human chromosomes. Cytogenetics and Cell Genetics 27: 190-193. doi: 10.1159/000131482

Solari S, Baker RJ (2006) Mitochondrial DNA sequence, karyotypic, and Morphological variation in the Carollia castanea species complex (Chiroptera: Phyllostomidae) with description of the new species. Occasional Paper of the Museum of Texas Tech University 254: 1-16.

Stock AD (1975) Chromosome banding pattern homology and its phylogenetic implications in the bat genera Carollia and Choeroniscus. Cytogenetics and Cell Genetics 14: 34-41. doi: $10.1159 / 000130317$

Sumner AT (1972) A simple technique for demonstrating centromeric heterochromatin. Experimental Cell Research 75: 304-306. doi: 10.1016/0014-4827(72)90558-7

Toledo LA (1973) Estudos citogenéticos em morcego brasileiros (Mammalia Chiroptera). Doctorship Thesis, Faculdade de Ciências Medicas e Biológicas de Botucatu, USP, Botucatu, Sao Paulo, Brasil, 90pp.

Varella-Garcia M, Morielle-Versute E, Taddei VA (1989) A survey of cytogenetic data on brazilian bats. Revista Brasileira de Genética 12: 761-793.

Verma RS, Babu A (1995) Human chromosomes: Principles and techniques. $2^{\text {nd }}$ ed., McgrewHill, inc. Health profession division, New York, 419 pp.

Volleth M, Klett C, Kollak A, Dixkens C, Winter Y, Just W, Vogel W, Hameister H (1999) ZOO-FISH analysis in a species of the order Chiroptera: Glossophaga soricina (Phyllostomidae). Chromosome Research 7: 57-64. doi: 10.1023/A:1009227428727

Wetterer AL, Rockman MV, Simmons NB (2000) Phylogeny of phyllostomid bats (Mammalia: Chiroptera): data from diverse morphological systems, sex chromosomes and restriction sites. Bulletin of the American Museum of Natural History, New York, 248: 1-200. doi: 10.1206/0003-0090(2000)248<0001:POPBMC>2.0.CO;2

Wright AJ, Van Den Bussche RA, Lim BK, Engstrom MD, Baker RJ (1999) Systematics of the genera Carollia and Rhinophylla based on the cytochrome-b gene. Journal of Mammalogy 80:1202-1213. doi: 10.2307/1383171

Yang F, Carter NP, Shi L, Ferguson-Smith MA (1995) A comparative study of karyotypes of muntjacs by chromosome painting. Chromosoma 103: 642-652. doi: 10.1007/ BF00357691

Yonenaga Y, Frota-Pessoa O, Lewis KR (1969) Karyotypes of seven species of Brazilian bats. Caryologia 22: 63-78. 